\title{
Oridonin promotes G2/M arrest in A549 cells by facilitating ATM activation
}

\author{
MINGXING ZHENG ${ }^{1}$, ZHIBING ZHU $^{2}$, YONGZHAO ZHAO ${ }^{3}$, DA YAO $^{4}$, MAOQING WU $^{5}$ and GENGYUN SUN ${ }^{6}$ \\ Departments of ${ }^{1}$ Respiratory Medicine and ${ }^{2}$ Gastrointestinal Surgery, Clinical College of \\ Anhui Medical University Affiliated Shenzhen Second People's Hospital, Shenzhen, Guangdong 518035; \\ ${ }^{3}$ School of Medicine, Tongji University, Shanghai 200092; ${ }^{4}$ Department of Thoracic Surgery, Clinical College \\ of Anhui Medical University Affiliated Shenzhen Second People's Hospital, Shenzhen, Guangdong 518035, P.R. China; \\ ${ }^{5}$ Renal Division, Department of Medicine, Brigham and Women's Hospital, Harvard Medical School, \\ Boston, MA 02115, USA; ${ }^{6}$ Department of Respiratory Medicine, The First Affiliated \\ Hospital of Anhui Medical University, Hefei, Anhui 230022, P.R. China
}

Received October 19, 2015; Accepted November 9, 2016

DOI: $10.3892 / \mathrm{mmr} .2016 .6008$

\begin{abstract}
Previous studies have demonstrated that oridonin, a tetracyclic diterpenoid compound extracted from Rabdosia rubescens, inhibits proliferation and induces apoptosis in several tumor cell lines. However, the mechanism by which oridonin inhibits the cell cycle remains poorly understood. In the present study, possible mechanisms by which oridonin affects cell cycle progression were explored in A549 lung cancer cells. Flow cytometry analysis indicated that oridonin inhibited the proliferation of A549 cells by inducing G2/M cell cycle arrest in a dose-dependent manner. Western blot analysis revealed that in oridonin treated cells, phosphorylated (p-)ATM serine/threonine kinase (S1981), p-checkpoint kinase 2 (CHK2) (T68), p-p53, and phosphorylated $\mathrm{H} 2 \mathrm{~A}$ histone family member $\mathrm{X}$ protein levels were visibly increased, indicating that oridonin promoted G2/M arrest in A549 cells through the ATM-p53-CHK2 pathway. This data suggests that oridonin promotes $\mathrm{G} 2 / \mathrm{M}$ arrest in A549 cells by facilitating ATM activation, which is likely a common mechanism in other tumor cell types when using this drug for cancer treatment.
\end{abstract}

\section{Introduction}

Lung cancer is a common malignancy and the leading cause of cancer-associated mortality worldwide (1). Non-small cell lung cancer (NSCLC) accounts for $~ 80 \%$ of lung cancers (2). Despite tremendous progress being made in

Correspondence to: Dr Gengyun Sun, Department of Respiratory Medicine, The First Affiliated Hospital of Anhui Medical University, 208 Jixi Road, Hefei, Anhui 230022, P.R. China

E-mail: sungengy@126.com

Key words: oridonin, A549 cells, cell cycle arrest, p53, ATM surgical techniques, chemotherapeutic agents, radiotherapy and novel molecular targeted drugs in previous decades, the prognosis of NSCLC remains poor, making the development of comprehensive treatments for the disease an urgent requirement. Oridonin, alternately known as guidongnin, is a tetracyclic diterpenoid compound extracted and purified from a traditional Chinese herb, Rabdosia rubescens, which is a member of the Salvia family. Previous studies have demonstrated that oridonin exhibits cytotoxicity, strong anti-tumor activity and is a powerful tumor suppressor (3-5). Oridonin directly inhibits the growth of $>20$ human cancer cell lines, including NB4 leukemia cells, A549 lung adenocarcinoma cells, HeLa cervical carcinoma cells, A357-S2 melanoma cells and SGC-7901 gastric cancer cells (6-10).

G2/M cell cycle arrest occurs when DNA is damaged, preventing cells from entering mitosis and providing an opportunity for DNA repair in order to maintain genomic stability (11-14). The ataxia telangiectasia mutated (ATM) gene encodes a serine/threonine protein kinase associated with DNA repair in an array of tumors $(12,13)$. As the product of the ATM gene, ATM possesses the property of autophosphorylation and is of vital significance to the DNA damage checkpoint, the repair of damaged DNA and apoptosis (11). Along with other proteins including p53 and checkpoint kinase (CHK2), ATM is involved in cell cycle arrest in response to situations where DNA is damaged (15).

The present study aimed to investigate whether cell cycle arrest contributes to oridonin-induced inhibition of proliferation, and attempted to explore the molecular mechanisms underlying this in A549 cells.

\section{Materials and methods}

Reagents and antibodies. Oridonin ( $\geq 98 \%$ ) was purchased from Shanghai Standard Technology Co., Ltd. (Shanghai, China) and dissolved in dimethyl sulfoxide (DMSO; final concentration $\leq 0.1 \%$ ). Dulbecco's modified Eagle's medium (DMEM) and calf serum were obtained from Gibco; Thermo 
Fisher Scientific, Inc. (Waltham, MA, USA). Antibodies of H2A histone family member X (H2AX; 1:100; cat. no. 7631), $\gamma$-H2AX (1:100 cat. no. 2577), ATM serine/threonine kinase (ATM; 1:500; cat. no. 2873), p-p53 (S15; 1:1,000; cat. no. 9286), checkpoint kinase 2 (CHK2; 1:1,000; cat. no. 3340), and p-CHK2 (T68; 1:500; cat. no. 2661) were purchased from Cell Signaling Technology, Inc. (Danvers, MA, USA). ATM pS1981 (1:100, cat. no. 200-301-400) was purchased from Rockland, Inc. (Limerick, PA, USA). Secondary antibodies goat anti-rabbit (1:5,000; cat. no. sc-2030) and goat anti-mouse $(1: 5,000$; cat. no. sc-2031.) were labeled with horseradish peroxidase. $\beta$-actin (cat. no. sc-47778; 1:1,000), lamin B (cat. no. sc-6217; 1:1,000) and p53 (cat. no. sc-6243; 1:200) antibodies were purchased from Santa Cruz Biotechnology, Inc. (Dallas, TX, USA). RNase and propidium iodide (PI) solution were purchased from Sigma-Aldrich; Merck Millipore (Darmstadt, Germany).

Cell culture. Human A549 lung cancer cells were purchased from China Center for Type Culture Collection of Wuhan University (Wuhan, China). Cells were cultured in DMEM supplemented with $10 \%$ calf serum and incubated in a humidified atmosphere $\left(5 \% \mathrm{CO}_{2}\right)$ at $37^{\circ} \mathrm{C}$. Cells were passaged routinely and logarithmically growing cells were used in the experiments as needed.

Flow cytometry. A549 cells $\left(\sim 1.0 \times 10^{4}\right)$ were treated for $48 \mathrm{~h}$ with DMSO or oridonin at different concentrations (16, 32 and $64 \mu \mathrm{mol} / \mathrm{l})$, collected and washed with phosphate-buffered saline (PBS) twice, followed by fixation with $70 \%$ ice-cold alcohol at $4^{\circ} \mathrm{C}$ for a least $1 \mathrm{~h}$. Cells were rinsed in ice-cold PBS twice, then suspended in $3 \mathrm{ml}$ PBS containing ribonuclease (Sigma-Aldrich; Merck Millipore) with the final concentration of $100 \mu \mathrm{g} / \mathrm{l}$. The cells were then incubated in a $37^{\circ} \mathrm{C}$ water-bath for $30 \mathrm{~min}$ and stained with $50 \mu \mathrm{g} / \mathrm{l} \mathrm{PI}$ for $30 \mathrm{~min}$ in the dark. The percentages of cells at different phases of the cell cycle were detected by flow cytometry (Cytoflex, Beckman Coulter, Inc., Brea, CA, USA), with absorbance measured at $488 \mathrm{~nm}$ (CytExpert, Beckman Coulter, Inc.).

Western blot. Oridonin or DMSO treated A549 cells were collected to a final concentration of $2 \times 10^{6}$ cells $/ \mathrm{ml}$. Proteins were extracted using a Protein Extraction Solution kit purchased from Beijing SBS Genetech Co., Ltd. (Beijing, China). Protein concentration was determined by bicinchoninic acid assay. Proteins were denatured in the presence of an equal volume of $2 \mathrm{X}$ sample buffer by boiling for $10 \mathrm{~min}$ at $95^{\circ} \mathrm{C}$ prior to SDS-PAGE. Following gel electrophoresis, the protein (50 $\mu \mathrm{g}$ per lane) was transferred onto a polyvinylidene difluoride membrane at $260 \mathrm{~mA}$ for $90 \mathrm{~min}$. The membrane was then blocked with TBS containing $5 \%$ bovine serum albumin (BSA, Thermo Fisher Scientific, Inc.), followed by incubation with primary antibody overnight at $4^{\circ} \mathrm{C}$. The membrane was subsequently washed four times with TBST (TBS plus $0.1 \%$ Tween-20) for $15 \mathrm{~min}$, and incubated with secondary antibody $(1: 1,000)$ for $1 \mathrm{~h}$ at room temperature. The membrane was then washed four times again in TBST for $15 \mathrm{~min}$ and the bound antibodies were detected using horseradish peroxidase-electrochemiluminescence. $\beta$-actin was used as a loading control. The Western blot results were repeated three times.
Table I. Effect of oridonin treatment on the cell cycle of A549 cells.

\begin{tabular}{llll}
\hline Group & G1 $(\%)$ & \multicolumn{1}{c}{$\mathrm{S}(\%)$} & $\mathrm{G} 2 / \mathrm{M}(\%)$ \\
\hline DMSO & $70.10 \pm 0.6$ & $19.73 \pm 0.8$ & $10.17 \pm 1.1$ \\
$16 \mu \mathrm{mol} / 1$ & $51.72 \pm 4.9$ & $31.24 \pm 3.89$ & $17.04 \pm 3.34^{\mathrm{a}}$ \\
$32 \mu \mathrm{mol} / 1$ & $46.68 \pm 5.1$ & $26.3 \pm 4.71$ & $27.02 \pm 4.43^{\mathrm{a}}$ \\
$64 \mu \mathrm{mol} / 1$ & $34.7 \pm 5.2$ & $17.23 \pm 4.89$ & $48.07 \pm 5.89^{\mathrm{a}}$ \\
\hline
\end{tabular}

${ }^{\mathrm{a} P}<0.05$ vs. DMSO group.

Immunofluorescence. Cells $\left(\sim 1 \times 10^{4}\right)$ were fixed with pre-chilled $\left(-20^{\circ} \mathrm{C}\right)$ acetone-methanol for $15 \mathrm{~min}$ and then blocked with $5 \% \mathrm{BSA}$ at room temperature for $1 \mathrm{~h} . \gamma$-H2AX and p-ATM (S1981) antibodies were added to the slides and incubated at $4^{\circ} \mathrm{C}$ overnight. Following washing, specimens were incubated with secondary antibodies for $1 \mathrm{~h}$ at room temperature. The cells were then covered with mounting medium containing 4',6-diamidino-2-phenylindole. Images were taken using SPOT 5.0 Advanced software (SPOT Imaging) with a Nikon TE1000 wide-field microscope system (Nikon).

Statistical analysis. Data were analyzed with SPSS 10.0 software (SPSS, Inc., Chicago, IL, USA) and are expressed as the mean \pm standard deviation if not otherwise indicated. Student's $t$-test was performed. $\mathrm{P}<0.05$ was considered to indicate a statistically significant difference.

\section{Results}

Oridonin induces cell cycle arrest at G2/M phase in A549 cells. To determine whether oridonin-induced cell cycle arrest contributes to tumor growth inhibition, A549 cells were exposed to oridonin at different concentrations (16, 32 and $64 \mu \mathrm{mol} / \mathrm{l}$ ) for $48 \mathrm{~h}$, and same volume of DMSO was administered as a vehicle control. Cells were subsequently harvested and cell cycle activity assessed by flow cytometry (Fig. 1). Quantitative analysis revealed that the proportion of G2/M phase cells was significantly increased, dose-dependently, in oridonin-treated A549 cells treated with $16(\mathrm{P}=0.014$; Table I), 32 ( $\mathrm{P}=0.009$; Table I) and $64 \mu \mathrm{mol} / 1$ oridonin $(\mathrm{P}=0.00003$; Table I) compared with DMSO-treated cells. By contrast, the proportion of G0/G1 phase cells decreased as a result of oridonin treatment compared with DMSO treatment (Table I). These results demonstrated that oridonin arrests A549 cells at the G2/M phase of the cell cycle in a dose-dependent manner.

Oridonin induces G2/M arrest by facilitating ATM activation in A549 cells. To investigate whether cell cycle-associated proteins $(\gamma$-H2AX, H2AX, lamin-B, p-ATM (S1981), ATM, p-CHK2 (T68), CHK2, p-p53 and p53) are involved in the oridonin-induced G2/M arrest in A549 cells, western blot was performed to evaluate the level of each protein. Following treatment with 16, 32 and $64 \mu \mathrm{mol} / 1$ oridonin, p-ATM (S1981), p-CHK2 (T68), p-p53, p53 and $\gamma$-H2AX protein levels in 

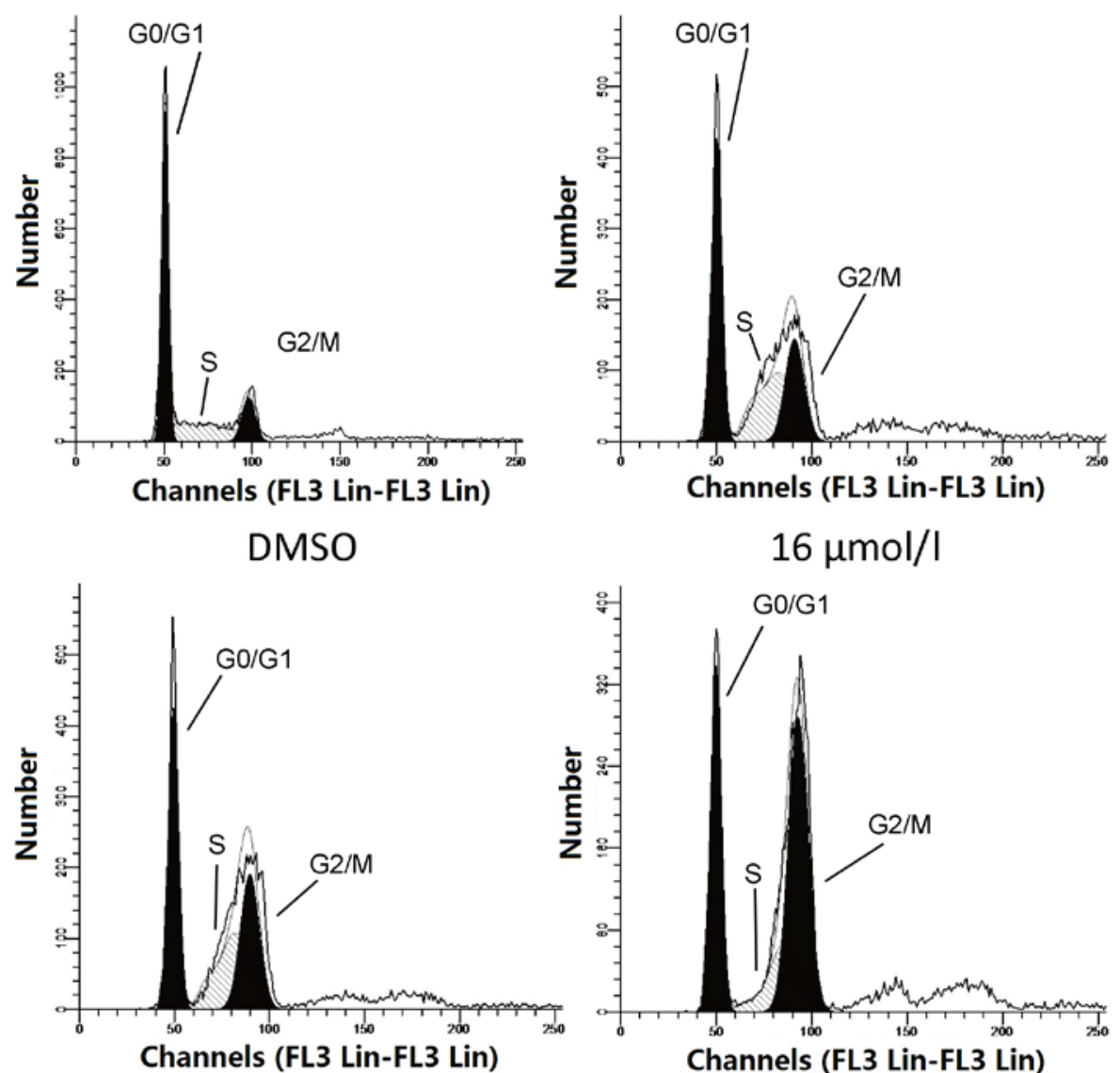

$32 \mu \mathrm{mol} / \mathrm{l}$

$16 \mu \mathrm{mol} / \mathrm{l}$

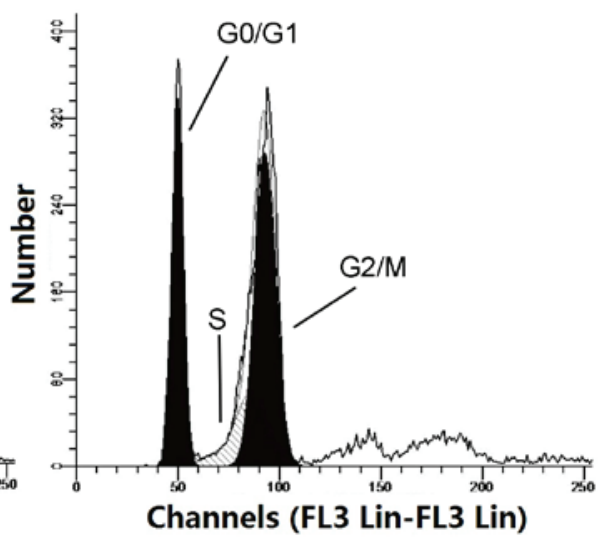

$64 \mu \mathrm{mol} / \mathrm{l}$

Figure 1. Oridonin treatment induces cell cycle arrest at G2/M, as demonstrated by flow cytometry. DMSO, dimethyl sulfoxide.

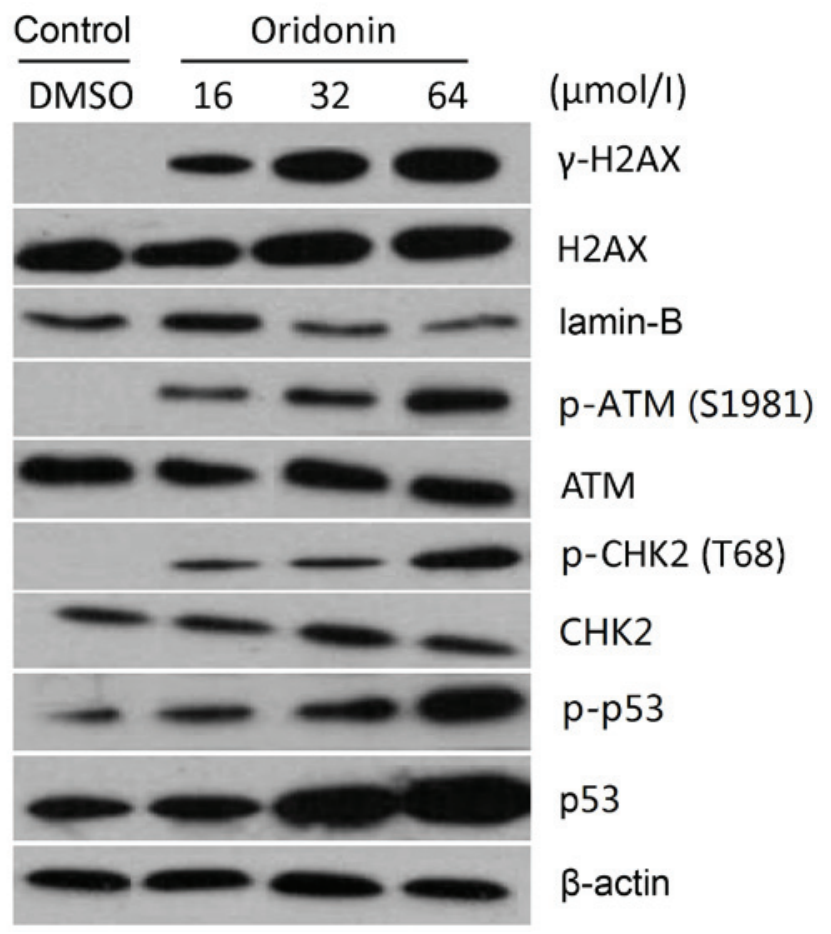

Figure 2. Oridonin treatment activates proteins involved in the ATM pathway. DMSO, dimethyl sulfoxide; $\gamma$-H2AX, phosphorylated $\mathrm{H} 2 \mathrm{~A}$ histone family member X; H2AX, H2A histone family member X; p-, phosphorylated; ATM, ATM serine/threonine kinase; CHK2, checkpoint kinase 2.
A549 cells increased (Fig. 2). The higher the concentration of oridonin used, the greater upregulation of p-ATM (S1981), p-CHK2 (T68), p-p53, p53 and $\gamma$-H2AX protein expression levels was presented (Fig. 2).

Effects of oridonin on $p$-ATM (S1981) and $\gamma$-H2AX. To further explore the function of p-ATM (S1981) and $\gamma$-H2AX on cell cycle arrest, A549 cells were treated with 16, 32 and $64 \mu \mathrm{mol} / 1$ oridonin and immunostaining was performed to investigate changes in expression of these two proteins. Both p-ATM (S1981) and $\gamma$-H2AX were upregulated following oridonin treatment (Fig. 3). Both p-ATM (S1981) and $\gamma$-H2AX were localized in the cell nucleus (Fig. 3).

\section{Discussion}

Lung cancer is one of the most common malignant tumors, and is associated with poor overall survival, therefore research into effective treatments is required (16). Previous in vitro studies have explored the anti-tumor effects of oridonin, and have demonstrated that it inhibits abnormal cell proliferation and induces apoptosis in various human tumor cell lines $(6,8,9,17-23)$.

The cell cycle is a fundamental cellular event, which is regulated at multiple levels by various factors in vitro and in vivo. Cell proliferation, division, apoptosis and necrosis 


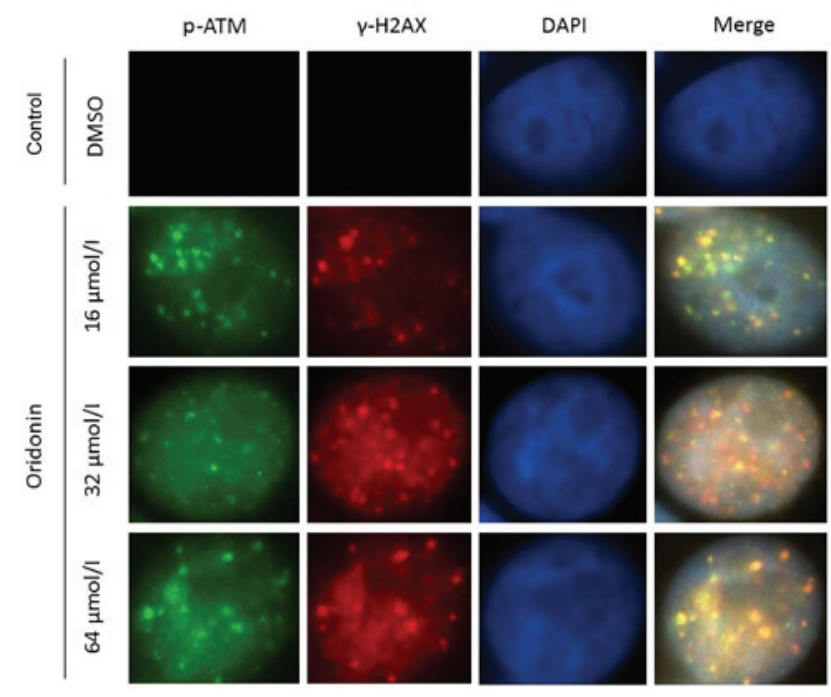

Figure 3. Oridonin treatment enhances nuclear expression levels of p-ATM (S1981); (green) and $\gamma$-H2AX (red). The nucleus is labelled with DAPI (blue). p-ATM, phosphorylated ATM serine/threonine kinase; $\gamma$-H2AX, phosphorylated H2A histone family member X; DMSO, dimethyl sulfoxide; DAPI, 4',6-diamidino-2-phenylindole.

all occur at certain phases in the cell cycle (24). Cells are programmed to enter pathological processes if certain phases of the cell cycle are abnormal (25). It is well established that cell cycle regulation is associated with the formation and development of tumors. Uncontrolled cell growth resulting from loss of cell cycle regulation is a characteristic common to almost all tumors (26). The G2/M phase checkpoint is the last opportunity for cell repair prior to mitosis (15). The present study demonstrated that the proportion of $\mathrm{G} 2 / \mathrm{M}$ phase cells significantly increased following treatment with 16, 32 and $64 \mu \mathrm{mol} / 1$ oridonin. Therefore, oridonin is able to induce cell cycle arrest at the G2/M checkpoint in A549 cells, and inhibit cell growth by interfering with mitotic progression.

DNA is constantly damaged by exogenous and endogenous factors during the cell cycle. Damaged DNA activates cell cycle checkpoints and induce cells to repair damaged DNA prior to entering the mitotic phase, so that genome integrity is maintained. Failure of DNA repair mechanisms or the accumulation of DNA damage-associated factors may lead to uncontrolled cell proliferation, which may eventually result in carcinogenesis. DNA damage induces phosphorylation of H2AX and activation of ATM and ATR serine/threonine kinase (ATR), which recognize DNA damage and transmit signals to downstream targets to promote cell cycle arrest, repair damaged DNA or induce apoptosis (27-29). Therefore, ATM and ATR are important for maintaining genomic stability and the prevention of tumorigenesis. p53 is an important tumor suppressor, originally identified as a protein bound to the large T antigen of the SV40 tumor virus (30). Mutations of p53 have been implicated in multiple human cancers (31). It has previously been demonstrated that p53 is involved in the DNA damage response and the inhibition of tumor growth (32). A previous study also revealed that p53 is involved in oridonin-induced cell cycle arrest in A549 cells (7).
The present study demonstrated that p-ATM (S1981), p-CHK2 (T68), p-p53, p53 and $\gamma$-H2AX protein levels were all increased in oridonin-treated cells, indicating that oridonin induces cell cycle arrest via activation of the ATM pathway. Damaged DNA induces H2AX protein phosphorylation to $\gamma$-H2AX, which subsequently activates ATM through autophosphorylation of ATM on Ser1981 (33-35). p-ATM (S1981) subsequently facilitates the phosphorylation and activation of $\mathrm{CHK} 2$ and p53, leading to cell cycle arrest (11). Oridonin activates proteins associated with multiple checkpoints, which trigger downstream cascade reactions and activates the network system regulated by ATM and ATR (15). With the participation of associated regulatory proteins, the induced proteins transfer DNA damage signals to downstream proteins of signal transduction and act on effector proteins, which may result in distinct effects including cell cycle arrest, apoptosis, DNA repair and transcriptional program activation induced through the ATM-p53-CHK2 pathway (36). As mentioned previously, DNA damage induces $\mathrm{H} 2 \mathrm{AX}$ phosphorylation, which is recognized as a DNA damage biomarker (37). In the present study, immunofluorescence staining data confirmed that oridonin treatment induced DNA damage, with increased levels of $\gamma$-H2AX in the nucleus of treated cells. Increased p-ATM (S1981) in the nucleus following oridonin treatment demonstrated that DNA damage resulted in increased levels of activated ATM in the cell nucleus.

To the best of our knowledge, this is the first report to demonstrate that oridonin-induced A549 cell cycle arrest occurs via activation of the ATM signaling pathway, although there are some limitations present. Downstream effector protein expression levels were not evaluated by western blotting, which prevented the investigation of detailed mechanisms underlying oridonin-induced cell cycle arrest in A549 cells. In addition, it remains unclear if ATM or CHK2 directly induced the activation of p53. Further experiments are required to address these questions.

In conclusion, the present study demonstrated that oridonin induces $\mathrm{G} 2 / \mathrm{M}$ cell cycle arrest through activating the ATM signaling pathway to inhibit proliferation in A549 cells. Future investigations may determine whether oridonin treatment induces the apoptosis of A549 cells.

\section{Acknowledgements}

The present study was supported by the Shenzhen Science \& Technology Research \& Development Project (grant no: JCYJ20130401112244855).

\section{References}

1. Torre LA, Bray F, Siegel RL, Ferlay J,Lortet-Tieulent J and Jemal A: Global cancer statistics 2012. CA Cancer J Clin 65: 87-108, 2015.

2. Molina JR, Yang P, Cassivi SD, Schild SE and Adjei AA: Non-small cell lung cancer: Epidemiology, risk factors, treatment, and survivorship. Mayo Clin Proc 83: 584-594, 2008.

3. Liu Z, Ouyang L, Peng H and Zhang WZ: Oridonin: Targeting programmed cell death pathways as an anti-tumour agent. Cell Prolif 45: 499-507, 2012.

4. Liu DL, Bu HQ, Jin HM, Zhao JF, Li Y and Huang H: Enhancement of the effects of gemcitabine against pancreatic cancer by oridonin via the mitochondrial caspase-dependent signaling pathway. Mol Med Rep 10: 3027-3034, 2014. 
5. Bu HQ, Luo J, Chen H, Zhang JH, Li HH, Guo HC, Wang ZH and Lin SZ: Oridonin enhances antitumor activity of gemcitabine in pancreatic cancer through MAPK-p38 signaling pathway. Int J Oncol 41: 949-958, 2012.

6. Liu J, Huang R, Lin D, Wu X, Peng J, Lin Q, Pan X, Zhang M, Hou M and Chen F: Apoptotic effect of oridonin on NB4 cells and its mechanism. Leuk Lymphoma 46: 593-597, 2005.

7. Liu Y, Liu JH, Chai K, Tashiro S, Onodera S and Ikejima T: Inhibition of c-Met promoted apoptosis, autophagy and loss of the mitochondrial transmembrane potential in oridonin-induced A549 lung cancer cells. J Pharm Pharmacol 65: 1622-1642, 2013.

8. Hu HZ, Yang YB, Xu XD, Shen HW, Shu YM, Ren Z, Li XM, Shen HM and Zeng HT: Oridonin induces apoptosis via PI3K/Akt pathway in cervical carcinoma HeLa cell line. Acta Pharmacol Sin 28: 1819-1826, 2007.

9. Zhang CL, Wu LJ, Tashiro S, Onodera S and Ikejima T: Oridonin induced A375-S2 cell apoptosis via bax-regulated caspase pathway activation, dependent on the cytochrome c/caspase-9 apoptosome. J Asian Nat Prod Res 6: 127-138, 2004.

10. Gao SY, Li J, Qu XY, Zhu N and Ji YB: Downregulation of Cdk1 and cyclinB1 expression contributes to oridonin-induced cell cycle arrest at G2/M phase and growth inhibition in SGC-7901 gastric cancer cells. Asian Pac J Cancer Prev 15: 6437-6441, 2014.

11. Boohaker RJ and $\mathrm{Xu}$ B: The versatile functions of ATM kinase Biomed J 37: 3-9, 2014.

12. Yan HQ, Huang XB, Ke SZ, Jiang YN, Zhang YH, Wang YN, Li J and Gao FG: Interleukin 6 augments lung cancer chemotherapeutic resistance via ataxia-telangiectasia mutated/NF-kappaB pathway activation. Cancer Sci 105: 1220-1227, 2014.

13. Hsia SM, Yu CC, Shih YH, Yuanchien Chen M, Wang TH, Huang YT and Shieh TM: Isoliquiritigenin as a cause of DNA damage and inhibitor of ataxia-telangiectasia mutated expression leading to G2/M phase arrest and apoptosis in oral squamous cell carcinoma. Head Neck 38 (Suppl 1): E360-E371, 2016.

14. Wang $\mathrm{H}$, Zhang X, Teng L and Legerski RJ: DNA damage checkpoint recovery and cancer development. Exp Cell Res 334: 350-358, 2015.

15. Stark GR and Taylor WR: Control of the G2/M transition. Mol Biotechnol 32: 227-248, 2006.

16. Oak CH, Wilson D, Lee HJ, Lim HJ and Park EK: Potential molecular approaches for the early diagnosis of lung cancer (review). Mol Med Rep 6: 931-936, 2012.

17. Tian W and Chen SY: Recent advances in the molecular basis of anti-neoplastic mechanisms of oridonin. Chin J Integr Med 19: 315-320, 2013

18. Li D, Xu S, Cai H, Pei L, Zhang H, Wang L, Yao H, Wu X, Jiang J, Sun $\mathrm{Y}$ and $\mathrm{Xu} \mathrm{J}$ : Enmein-type diterpenoid analogs from natural kaurene-type oridonin: Synthesis and their antitumor biological evaluation. Eur J Med Chem 64: 215-221, 2013

19. Ikezoe T, Chen SS, Tong XJ, Heber D, Taguchi H and Koeffler HP: Oridonin induces growth inhibition and apoptosis of a variety of human cancer cells. Int J Oncol 23: 1187-1193, 2003.

20. Chen G, Wang K, Yang BY, Tang B, Chen JX and Hua ZC: Synergistic antitumor activity of oridonin and arsenic trioxide on hepatocellular carcinoma cells. Int J Oncol 40: 139-147, 2012.
21. Liu Y, Liu YZ, Zhang RX, Wang X, Meng ZJ, Huang J, Wu K, Luo JY, Zuo GW, Chen L, et al: Oridonin inhibits the proliferation of human osteosarcoma cells by suppressing Wnt/ $\beta$-catenin signaling. Int J Oncol 45: 795-803, 2014

22. Gao FH, Liu F, Wei W, Liu LB, Xu MH, Guo ZY, Li W, Jiang B and $\mathrm{Wu}$ YL: Oridonin induces apoptosis and senescence by increasing hydrogen peroxide and glutathione depletion in colorectal cancer cells. Int J Mol Med 29: 649-655, 2012.

23. Bu HQ, Liu DL, Wei WT, Chen L, Huang H, Li Y and Cui JH: Oridonin induces apoptosis in SW1990 pancreatic cancer cells via p53- and caspase-dependent induction of p38 MAPK. Oncol Rep 31: 975-982, 2014.

24. Evan GI and Vousden KH: Proliferation, cell cycle and apoptosis in cancer. Nature 411: 342-348, 2001.

25. Kikuchi K, Hettmer S, Aslam MI, Michalek JE, Laub W, Wilky BA, Loeb DM, Rubin BP, Wagers AJ and Keller C: Cell-cycle dependent expression of a translocation-mediated fusion oncogene mediates checkpoint adaptation in rhabdomyosarcoma. PLoS Genet 10: e1004107, 2014.

26. Schafer KA: The cell cycle: A review. Vet Pathol 35: 461-478, 1998.

27. Falck J, Coates J and Jackson SP: Conserved modes of recruitment of ATM, ATR and DNA-PKcs to sites of DNA damage. Nature 434: 605-611, 2005.

28. Jazayeri A, Falck J, Lukas C, Bartek J, Smith GC, Lukas J and Jackson SP: ATM- and cell cycle-dependent regulation of ATR in response to DNA double-strand breaks. Nat Cell Biol 8: 37-45, 2006.

29. Lee JH and Paull TT: ATM activation by DNA double-strand breaks through the Mre11-Rad50-Nbs1 complex. Science 308: $551-554,2005$.

30. Oren $\mathrm{M}$ and Rotter V: Introduction: p53-the first twenty years. Cell Mol Life Sci 55: 9-11, 1999.

31. Meek DW: Regulation of the 553 response and its relationship to cancer. Biochem J 469: 325-346, 2015.

32. Wang X, Simpson ER and Brown KA: p53: Protection against tumor growth beyond effects on cell cycle and apoptosis. Cancer Res 75: 5001-5007, 2015.

33. Douglas P, Zhong J, Ye R, Moorhead GB, Xu X and Lees-Miller SP: Protein phosphatase 6 interacts with the DNA-dependent protein kinase catalytic subunit and dephosphorylates gamma-H2AX. Mol Cell Biol 30: 1368-1381, 2010.

34. Kinner A, Wu W, Staudt C and Iliakis G: Gamma-H2AX in recognition and signaling of DNA double-strand breaks in the context of chromatin. Nucleic Acids Res 36: 5678-5694, 2008.

35. Bakkenist CJ and Kastan MB: DNA damage activates ATM through intermolecular autophosphorylation and dimer dissociation. Nature 421: 499-506, 2003.

36. Reinhardt HC and Yaffe MB: Kinases that control the cell cycle in response to DNA damage: Chk1, Chk2 and MK2. Curr Opin Cell Biol 21: 245-255, 2009.

37. Gerić M, Gajski G and Garaj-Vrhovac V: $\gamma-\mathrm{H} 2 \mathrm{AX}$ as a biomarker for DNA double-strand breaks in ecotoxicology. Ecotoxicol Environ Saf 105: 13-21, 2014. 